\title{
Um ponto de vista e a identificação de perspectivas desafiadoras
}

Maria Cristina Oliveira Bruno'

DOI 10.265I 2/museologia.v8il6.27325

\begin{abstract}
Resumo
O texto apresenta a trajetória do ensino da Museologia no país, a partir de um ponto de vista retrospectivo entre as realidades, as utopias e os embates, sublinhando os desafios atuais.
\end{abstract}

Palavras-chave:

Museologia. Formação Profissional. Democracia. Utopia. Memória.

\begin{abstract}
The text presents the trajectory of the teaching of Museology in the country, from a retrospective point of view between realities, utopias and clashes, highlighting the current challenges.
\end{abstract}

\section{Keywords:}

Museology. Vocational Training. Democracy. Utopia. Memory.

\section{Considerações Iniciais}

A partir da minha experiência como estudante, museóloga e professora do campo da Museologia, ao longo dos últimos 40 anos, tem sido possível delinear um ponto de vista sobre a trajetória da formação profissional neste país e suas reciprocidades com os outros campos de conhecimento que também atuam no universo museológico e, ainda, buscar análises comparativas com cenários estrangeiros.

Mas, sobretudo, tem sido necessário identificar os desafios que cotidianamente se apresentam neste cenário, se renovam e se reinventam. Esse esforço de definir um olhar particular e singular sobre a realidade que nos envolve e, ao mesmo tempo, buscar compreender conjunturas mais amplas e complexas, tem colaborado para a construção da minha convicção de que a Museologia tem um papel a ser desempenhado nas conquistas democráticas da nossa sociedade e é fundamental para a consolidação dos museus.

E mesmo envolvida em muitas circunstâncias sociopolítico-culturais e educacionais, de difíceis manejos, a Museologia está inserida nas idas e vindas dos nossos complexos processos de democratização, tanto do ponto de vista do alargamento de suas premissas teóricas quanto no acolhimento de perspectivas metodológicas mais participativas e inclusivas.

Apesar de uma percepção mais ampla do contexto em que estamos envolvidos, com experiências fundamentais vivenciadas em diferentes regiões do país, não posso deixar de registrar que a minha percepção e a minha convicção são moldadas pela minha experiência particular a partir de São Paulo e de um contexto universitário.

É uma reflexão permeada, cabe lembrar, por um ponto de vista de uma profissional que sempre procurou aliar o trabalho cotidiano nos museus, com o exercício da docência em Museologia e com a militância pelo reconhecimento

I Professora Titular em Museologia do Museu de Arqueologia e Etnologia da Universidade de São Paulo, integrada ao Programa de Pós-Graduação Interunidades em Museologia / USP. 
deste campo de atuação acadêmica.

A partir dessas considerações iniciais, gostaria de apresentar a minha contribuição compartilhando as minhas ideias em dois segmentos: embates.

I. Um ponto de vista retrospectivo entre as realidades, as utopias e os

2. Os desafios que temos pela frente.

\section{Um ponto de vista retrospectivo entre as realidades, as utopias e os embates}

As distintas vertentes que contribuem e em algumas circunstâncias concorrem para a formação profissional para os museus brasileiros, entre as quais a Museologia se enquadra, registram trajetória longa com momentos significativos, modalidades diferenciadas, fases permeadas por estranhamentos entre pares e vulnerabilidades em relação a problemas contemporâneos.

Reconhecemos que diferentes profissões atuam nessas instituições, evidenciando sua vocação interdisciplinar e multiprofissional, mas também verificamos que os profissionais formados em Museologia atuam em outros modelos institucionais, para além dos museus.

Assim, ponderamos que ao longo dos anos este cenário profissional se tornou híbrido. Entretanto, neste momento, nos cabe buscar análises e justificativas para a projeção da Museologia neste contexto.

Esta apresentação privilegiará questões que envolvem a formação em Museologia e o museu (em suas variadas dimensões) como espaço especial para atuação dos profissionais formados neste âmbito, valorizando algumas conquistas democráticas, mas também, os riscos que identificamos nos últimos anos.

A formação profissional em Museologia registra trajetória não linear, mas com momentos significativos, com esforços de muitas gerações de técnicos e professores, de modalidades diferenciadas de ensino, mas, especialmente, permeada por utopias e conquistas sistemáticas. Mas tem sido também uma trajetória de muitos embates internos ao próprio campo e externos em relação a pelo menos dois contextos: limites e reciprocidades acadêmicas e o papel dos museus na sociedade.

A profissionalização em Museologia, entre nós, como sabemos, data de 1932 com o primeiro curso técnico (Curso de Museus) instalado no Rio de Janeiro, hoje vinculado à UNIRIO e desde a década de 1970 estruturado de acordo com os parâmetros da formação universitária.

Essa primeira experiência que carrega os elementos do "mito de origem" da profissionalização foi desdobrada, de forma indireta, ao longo das décadas de 1950 e 1960, em diferentes modalidades de cursos de curta duração dispersos por diversas regiões do país, despertando a vocação de muitos professores do ensino fundamental e médio para as preocupações patrimoniais com a História e Arte. Concomitantemente, os grandes centros brasileiros acolheram outras experiências estrangeiras, repassadas em cursos de diferentes modalidades e aplicados para distintas tipologias de museus.

Essa iniciativa pioneira do Rio de Janeiro só foi desdobrada de forma direta, mas com matizes muito distintos, na década de 1970 com a implantação de outro curso congênere na Universidade Federal da Bahia, provocando alterações neste cenário que foram ampliadas com as novidades provenientes de 
outra modalidade para formação profissional. Refiro-me ao Curso de Especialização em Museologia da Fundação Escola de Sociologia de São Paulo, criado em 1978. Considero que este momento, final da década de 1970, representa 0 início de uma quebra de hegemonia sobre como deveria ser a formação em Museologia e ao mesmo tempo o surgimento de uma trajetória de embates muito significativos.

É importante registrar que estes três polos de formação profissional em Museologia, apesar de suas diferenças e com distintas ênfases, participaram ativamente das ações para a regulamentação da profissão do museólogo, ocorrida em 1984, e do movimento Diretas Já, marco significativo do processo de redemocratização do Brasil. Essas ações foram responsáveis pela criação de associações de profissionais e pelos conselhos regionais e Conselho Federal de Museologia.

É possível considerar que este foi um período de forte expressão "intramuros", com buscas direcionadas para as especificidades do campo da Museologia e do exercício da profissão do museólogo.

Cabe sublinhar que os anos entre as décadas de 1980 e 1990 registraram diversas iniciativas com perfil acadêmico - mesmo externas às universidades como por exemplo, as diversas edições do Fórum Nordestino de Museologia e dos Encontros Paulistas de Museólogos. É também desta fase a nossa conexão de forma mais sistemática e plural com as iniciativas do ICOM/Conselho Internacional de Museus.

As décadas que separaram a primeira iniciativa dessa fase de proliferação de caminhos contaram, ainda, com diversas realizações de projetos de capacitação profissional a partir do entusiasmo de autodidatas, de profissionais de outros campos, de colecionadores, de artistas, entre muitos outros entusiastas da importância dos museus para a educação que, em diferentes regiões brasileiras, semearam a utopia e o germe da educação a partir das instituições que colaboram com a administração da memória.

É também deste período a primeira dissertação de mestrado elaborada em torno de problemas museológicos - "Museus: um aspecto das organizações culturais num país em desenvolvimento" - de Waldisa Rússio Camargo Guarnieri (1977), seguida de uma intensa produção de monografias, dissertações e teses até os dias de hoje.

Apesar desta ênfase dada ao processo de redemocratização e mesmo apontando que a Museologia se movimentava em um cenário híbrido, não podemos deixar de sublinhar que a perseguição e as delações entre pares, referentes aos profissionais e cursos que tinham enquadramentos acadêmicos distintos, foram intensas e provenientes da própria área.

A entrada do século XXI foi acompanhada por uma mobilização grande dos profissionais e estudantes do campo da Museologia, para além das duas graduações já consagradas, que podemos entender em três segmentos:

a) Ampliação das oportunidades de formação no âmbito das universidades a partir da implantação de cursos de especialização em diferentes regiões, causando expressivos estranhamentos e embates no âmbito da própria área e dificultando a inserção dos egressos no campo profissional;

b) A formulação do documento para a Política Nacional de Museus (2003) no âmbito do Ministério da Cultura e o gradativo, mas intenso e sistemático processo de consolidação do campo museal que, em conjunto com o Ministério da Educação, abriu novas perspectivas para a implantação de graduações 
em todas as regiões do país, abrindo novas rotas de interlocução com outros campos de formação profissional, trazendo à luz a necessidade de discussões e entendimentos sobre os parâmetros elementares para a formação em Museologia;

c) A implantação de programas de pós-graduação em diferentes regiões, como Rio de Janeiro, São Paulo, Bahia, Piauí, Rio Grande do Sul, que tem permitido o crescimento sistemático dos trabalhos acadêmicos que divulgam e analisam as nossas realidades museológicas, mas que enfrentam o singular desafio de se colocarem como Área nos contextos das políticas públicas de pós-graduação, notadamente da CAPES / Coordenação de Aperfeiçoamento de Pessoal de Nível Superior do Ministério da Educação.

Durante esse período também registramos - novamente - centenas de cursos, oficinas, capacitações profissionais, nas mais variadas modalidades significativas do campo museal e identificamos a criação de muitas redes e sistemas de museus que também têm dedicado atenção à formação profissional.

As conexões entre estudantes, professores e profissionais em geral e as experiências e as bibliografias internacionais já fazem parte do nosso cotidiano, facilitadas pelas mídias eletrônicas, pela atuação do Conselho Internacional de Museus e de outras organizações estrangeiras que atuam na nossa área.

Em menos de dois séculos a formação profissional migrou de uma trajetória singular para um contexto caleidoscópico, como também, acompanhou e impulsionou mudanças significativas referentes à função social das instituições museológicas.

Nesse período, a Museologia tem recebido distintas qualificações: Nova Museologia, Museologia Social, Museologia Experimental, Sociomuseologia que às vezes são apresentadas como qualificações sinônimas. A Museologia também tem se encaixado e se conectado com outros campos, tais como: Educação Museal, Musealização da Arqueologia, Museologia Antropológica, entre outros, evidenciando a fluidez que tem permeado as margens entre as ciências e projetado estas para um embate social mais multifacetado.

Ainda expressando o meu ponto de vista, entendo que o campo de formação profissional em Museologia, no Brasil, carece de muito diálogo entre aqueles que optaram ou foram levados para a atuação nesta área. Entender as formas a partir das quais podemos interagir com as nossas realidades e desenhar novas utopias exigem ainda muito esforço, pois estamos apenas começando.

E lembrando as palavras de Waldisa Rússio Camargo Guarnieri: "há, na realidade, uma museologia existente, real, que está aí fora, e há uma museologia postulada, sonhada, desejada." (Rússio, 1984, p. 65)

Pergunto-me o que mudou desta museologia existente que Waldisa observava e interagia e no que caminhamos na postulação de uma museologia sonhada e desejada? Da mesma forma faço indagações em relação às palavras de Mario de Andrade quando em 1932 se referiu aos museus:

Porém, a sua transformação técnica não é o que nos interessa aqui. Muito mais importante foi a sua transformação, por assim dizer moral. Mas é que o verdadeiro museu não ensina a repetir o passado, porém a tirar dele tudo quanto ele nos dá dinamicamente para avançar em cultura dentro de nós, e em transformação dentro do processo social (Andrade, 1938, p. 53). 

moral?

Pergunto-me ao que ele se referia quando falava de uma transformação

Procuro cotidianamente respostas a estas perguntas quando penso em nossas responsabilidades como profissionais do campo da Museologia e, principalmente, quando procuro caminhos para o enfrentamento dos desafios.

\section{Os desafios que temos pela frente}

Essas breves palavras que explicitam o meu ponto de vista sobre alguns elementos da trajetória da formação em Museologia entre nós, e considerando o momento que estamos vivendo, fazem emergir quatro inflexões sobre:

I. A necessidade de renovação constante dos parâmetros que identificam o que se espera dos profissionais egressos das graduações em Museologia, à luz dos novos desafios acadêmicos que têm norteado a fluidez entre os campos de conhecimento:

- o que é o específico?

- como construir a interdisciplinaridade?

- como atuar em cenários multiprofissionais?

2. A importância da constituição de um tipo de "observatório nacional" que permita aos programas de pós-graduação constituírem, em diálogo, os parâmetros para as suas avaliações acadêmicas e, ao mesmo tempo, identificarem os principais problemas a serem tratados nas dissertações e teses com vistas às abordagens de relevância nacional, mas com impactos regionais;

3. A incorporação de experiências metodológicas de ensino que capacitem os estudantes para o domínio das ações museológico-curatoriais, mas também, para a análise de conjunturas socioculturais e as respectivas qualificações das intervenções museológicas, ou seja: capacitar os estudantes para o exercício técnico de atividades intramuros dos museus e, ao mesmo tempo, prepará-los para ações comunitárias colaborativas e compartilhadas;

4. A facilidade de interlocução com os mais variados organismos nacionais e internacionais que têm se organizado, atuado e influenciado também no campo da formação profissional. Refiro-me às ONGs / Organizações Não-Governamentais; às instituições das áreas de entretenimento; às redes que atuam não só no campo de museus, que de certa forma, repercutem na relevância das universidades, do ICOM, dos sistemas nacionais e regionais, no que diz respeito aos parâmetros para a formação profissional no contexto museológico.

Essas inflexões aqui propostas (com um viés doméstico de lição de casa para todos nós) que, de alguma forma, sinalizam para os desafios deste momento, não devem nos afastar da necessária produção teórica, de novas experimentações metodológicas e da construção dos processos sobre as historicidades dos fenômenos museológicos.

Mais ainda, não podem nos afastar da abordagem de temas que têm provocado a atualização dos museus como as questões de gênero, das memórias dolorosas, das conjunturas étnicas e socioculturais que ainda ficam à margem das ações museológicas, dos dilemas de museus com ou sem acervo, das conquistas tecnológicas, dos desafios referentes ao enfrentamento das políticas de segurança das instituições, entre centenas de temas. Tudo isso nos diz respeito.

A partir do exposto e de acordo com o que o meu ponto de vista me 
permite enxergar quando procuro visualizar o que envolve a formação profissional, e para finalizar, mesmo reconhecendo que o campo da Museologia tem sido delineado a partir de distintas linhas de elaboração teórica e experimentação metodológica, gostaria de compartilhar também o meu ponto de vista neste contexto em quatro tópicos:

I. A relevância do campo da Museologia considerar que os indicadores de memórias e as referências culturais constituem o ponto de partida para a identificação da musealidade e a respectiva aplicação de procedimentos museológico-curatoriais para a construção dos processos de musealização, e a relevância de prepararmos profissionais para a atuação neste contexto;

2. A importância de buscarmos caminhos para que os processos de musealização tenham a capacidade de mobilização social, considerando as metodologias participativas e colaborativas;

3. A verificação sobre as estratégias para que o campo da Museologia se integre a ações interdisciplinares e faça parte de cenários multiprofissionais, sem perder a sua especificidade no que se refere ao tratamento e projeção da herança cultural e sua consolidação no campo da administração da memória, da educação para o patrimônio e do desenvolvimento social;

4. A pertinência de diálogo entre os estudos museológicos e os estudos históricos e antropológicos que permitem ampliar a nossa compreensão sobre as distintas inserções dos museus / processos museológicos ao longo do tempo e em distintas sociedades.

Considerando os pontos aqui compartilhados, gostaria de enfatizar que as ações museológicas, em algumas dimensões, têm relevância nos enquadramentos democráticos e para continuarmos neste circuito é preciso reconhecer que hoje a Museologia transita entre os desafios do:

- dever de memória;

- desejo de memória;

- direito à memória.

\section{Referências}

ANDRADE, Mario de. Museus Populares. Problemas. Revista Mensal de Cultura, São Paulo, a.I - 5, seção Arte, p. 53-55, 1938.

RUSSIO, Waldisa. Cultura, patrimônio e preservação (Texto III). In: ARANTES, Antônio Augusto (Org.). Produzindo o Passado: Estratégias de Construção do Patrimônio Cultural. São Paulo: Brasiliense, 1984. 